\title{
cmaJOPEN
}

\section{Comparison of claims from high-drug cost beneficiaries in Ontario, Canada, and Australia: a cross-sectional analysis}

\author{
Mina Tadrous PharmD PhD, Benjamin Daniels MA PhD, Sallie-Anne Pearson PhD, Tara Gomes MHSc PhD
}

\section{Abstract}

Background: Globally, payers are struggling with rising drug costs, driven primarily by the increasing number of high-cost medications used by their beneficiaries. We aimed to compare the annual drug spending on claims from high-drug cost beneficiaries in the province of Ontario, Canada, and Australia.

Methods: We conducted a cross-sectional analysis of public drug claims in Ontario and Australia from fiscal years 2006 to 2017 . We identified the total government costs for prescribed medications per beneficiary. During the study period, public drug coverage in Ontario was provided to all residents 65 years of age and older, those with financial needs, and those living in long-term care or in need of home care. Australia maintains a publicly funded, universal system covering all citizens. Based on annual spending, we divided beneficiaries into 4 cost groups, representing the top 1\%, top 5\%, top 10\% and the remaining $90 \%$. We reported the following for each cost group: medication cost and proportion of total government spending, number of unique drugs dispensed per person and the top 10 most costly drug classes.

Results: In Ontario and Australia, the top 1\% of beneficiaries accounted for a large and increasing proportion of all government drug costs, growing from 12\% (\$405 946197$)$ to 24\% (\$1 345977248$)$ in Ontario, and from 14\% (\$86 565 586) to 34\% (\$416 097 984) in Australia between 2006 and 2017. The most costly drug classes among high-drug cost beneficiaries in both jurisdictions were biologics and hepatitis $\mathrm{C}$ treatments.

Interpretation: In both Ontario and Australia, a small number of beneficiaries accounted for a large proportion of public drug spending, driven largely by the use of expensive medications. The current development of potential national pharmacare strategies in Canada must optimize the use of high-cost drugs to ensure the sustainability of the program.

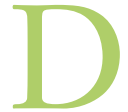
rug costs account for a sizable expenditure in health care systems around the world ${ }^{1,2}$ Globally, drug spending has grown $36 \%$, from $\$ 886$ billion to $\$ 1.2$ trillion between 2010 and 2018. The rise in expenditure is outpacing spending on hospitals and physicians in most Organisation for Economic Co-operation and Development countries. ${ }^{3,4}$ This growth in pharmaceutical expenditures is likely associated with an increase in overall drug use in an aging population, as well as a growing number of new therapies with very high price tags. ${ }^{5}$ Higher costs have been associated with a high level of clustering by beneficiaries of public drug programs, in which a small number of individuals account for a large proportion of total expenditures. ${ }^{6}$ Higher costs have also been associated with clustering in overall health care expenditures. ${ }^{7-12}$ It is unclear to what extent the overall growth in drug expenditure is driven by this same occurrence.

Canada is currently the only high-income country with a universal health insurance system that does not provide universal coverage of prescription drugs,,$^{13}$ in contrast to Australia, which has a publicly funded Pharmaceutical Benefits
Scheme (PBS). Recently, there has been increasing pressure to establish a national drug coverage program in Canada, similar to Australia's PBS..$^{14,15}$ Therefore, understanding the role of high-cost beneficiaries in pharmaceutical expenditures in a similar health care system with universal coverage, such as Australia, would offer important insights for policy development of any national strategy. We aimed to describe the patterns and trends for spending on drugs for high-cost beneficiaries from Ontario and Australia between 2006 and 2017.

Competing interests: Mina Tadrous reports consulting fees from Green Shield Canada and the Canadian Agency for Drugs and Technologies in Health, and Benjamin Daniels and Sallie-Anne Pearson report funding from Abbvie, outside the submitted work. No other competing interests were declared.

This article has been peer reviewed.

Correspondence to: Mina Tadrous, mina.tadrous@utoronto.ca CMAJ Open 2021 November 23. DOI:10.9778/cmajo.20200291 


\section{Methods}

\section{Design}

We conducted a cross-sectional study of active public drug plan beneficiaries residing in Ontario and Australia. We defined active beneficiaries in Ontario as individuals who had at least 1 prescription reimbursed by a provincial public drug program between Apr. 1, 2006, and Mar. 31, 2018 (Canadian fiscal years 2006 to 2017). We defined active beneficiaries in Australia as individuals dispensed at least 1 PBS-subsidized prescription medication between Jan. 1, 2006, and Dec. 31, $2017 .{ }^{14}$

\section{Setting and data sources}

We used data capturing publicly funded prescription medicine claims from Ontario and Australia. In Ontario, we identified all publicly funded drug claims using the Ontario Drug Benefit database. ${ }^{16}$ In Australia, we used PBS dispensing data from a random $10 \%$ sample of all PBS-eligible Australian citizens and permanent residents. ${ }^{14}$ Both the Ontario and Australian data contain complete dispensing details (i.e., date of dispensing, medication name, strength, quantity). Neither data set captures information about private prescriptions or overthe-counter medications.

\section{Participants}

Over the study period, public coverage in Ontario was provided to all residents 65 years of age and older, residents with financial needs (from high drug costs or low income), and those living in long-term care or in need of home care. In Ontario, most residents (about 70\%) younger than age 65 do not meet 1 of the criteria listed and would not be included in this data set. Australia maintains a publicly funded, universal system that entitles all citizens and residents to subsidized medicines through the PBS.

\section{Statistical analysis}

Our analysis included all prescription drug claims paid for by the Ontario Drug Benefit and the PBS. We excluded claims for services that are reimbursed by the provincial government for all Ontarians (regardless of eligibility for public drug programs), including vaccinations and professional pharmacy services.

We did not include out-of-pocket copayment. Both jurisdictions have small copayments that vary by financial status. We also excluded all cancer treatments to allow for comparability between jurisdictions, as cancer treatments are reimbursed differently in each jurisdiction. In Australia, most cancer medicines are funded through the Efficient Funding of Chemotherapy Program, ${ }^{14,15,17}$ which aims to reduce medicine waste and costs by funding the lowest cost combination of vials. Many cancer treatments are captured in PBS dispensing data, but a suffficient number are not captured such that any cost estimates we might calculate would not be accurate. Similarly, in Ontario, only a small proportion of cancer treatments are dispensed through the public drug program, limited mostly to oral therapies; most other therapies are dispensed through hospitals, paid for by the cancer program budget.
We report costs for the Ontario data in Canadian dollars and report the Australian data in Australian dollars. We also conducted a secondary analysis in which we converted cost thresholds from Australian dollars to Canadian dollars using the annual conversion rates based on exchange rates from xe.com.

We identified the total number of active beneficiaries and their associated annual cost to the public payers in each jurisdiction. We stratified the beneficiaries into 4 groups, the top $1 \%$, top $5 \%$, top $10 \%$ and bottom $90 \%$, in terms of cost to the payer. We selected these cut-offs to align with previous work describing the distribution of health care spending. $6,11,12,18-21$

We defined costs as the total amount paid by the public payer, excluding deductibles and out-of-pocket payments. For each fiscal year and beneficiary group, we reported total drug costs, minimum cost threshold (defined as the beneficiary with the lowest total drug spend in each group), median number of unique drugs dispensed in the year per person and the top 9 most costly reimbursed medications among high-drug cost beneficiaries (in the upper $5 \%$ of total spending only). Medications were presented at the therapeutic subgroup (Anatomical Therapeutic Chemical level 2) and drug name level. ${ }^{22}$

\section{Ethics approval}

The use of data in this project was authorized under section 45 of Ontario's Personal Health Information Protection Act, which does not require review by a research ethics board. In Australia, ethics approval for our study was granted by the New South Wales Population \& Health Services Research Ethics Committee (approval number 2013/11/494).

\section{Results}

Figure 1 illustrates the proportions of total annual spending for publicly funded drugs among beneficiaries in Australia and Ontario from 2006 to 2017. The proportions of spending attributed to high-drug cost beneficiaries grew over the study period in both jurisdictions. Spending increased for the top $1 \%$ in Ontario, from Can\$405 946197 (11.6\% of all drug costs) to Can\$1 345977248 (23.6\%). Similarly, in Australia, spending grew from A\$ 664722930 (11.2\% of all drug costs) in 2006 to A\$3 252904140 (30.3\%) in 2017.

We also observed expenditure increases for the top 5\% and $10 \%$ of beneficiaries in both jurisdictions. In Ontario, costs for the top 5\% climbed from Can\$1 003619650 (28.6\%) to Can\$2 656666293 (46.5\%), and from Can\$1 478719297 (42.2\%) to Can\$3 394479306 (59.4\%) for the top 10\%. In Australia, costs increased from A\$1 812622200 (30.6\%) in 2006 to A\$5 697182300 (53.1\%) in 2017 for the top 5\%, and from A\$2 757614370 (46.5\%) to A\$6 947542570 (64.8\%) for the top $10 \%$.

\section{Minimum cost thresholds}

The minimum spend (i.e., cost threshold) on medications for high-drug cost beneficiaries increased in both jurisdictions across all high-cost beneficiary categories (Figure 2). The cost threshold for the top $1 \%$ increased in Ontario, from Can\$10 151 in 2006 to Can\$20 437 in 2017, a 101\% increase. 


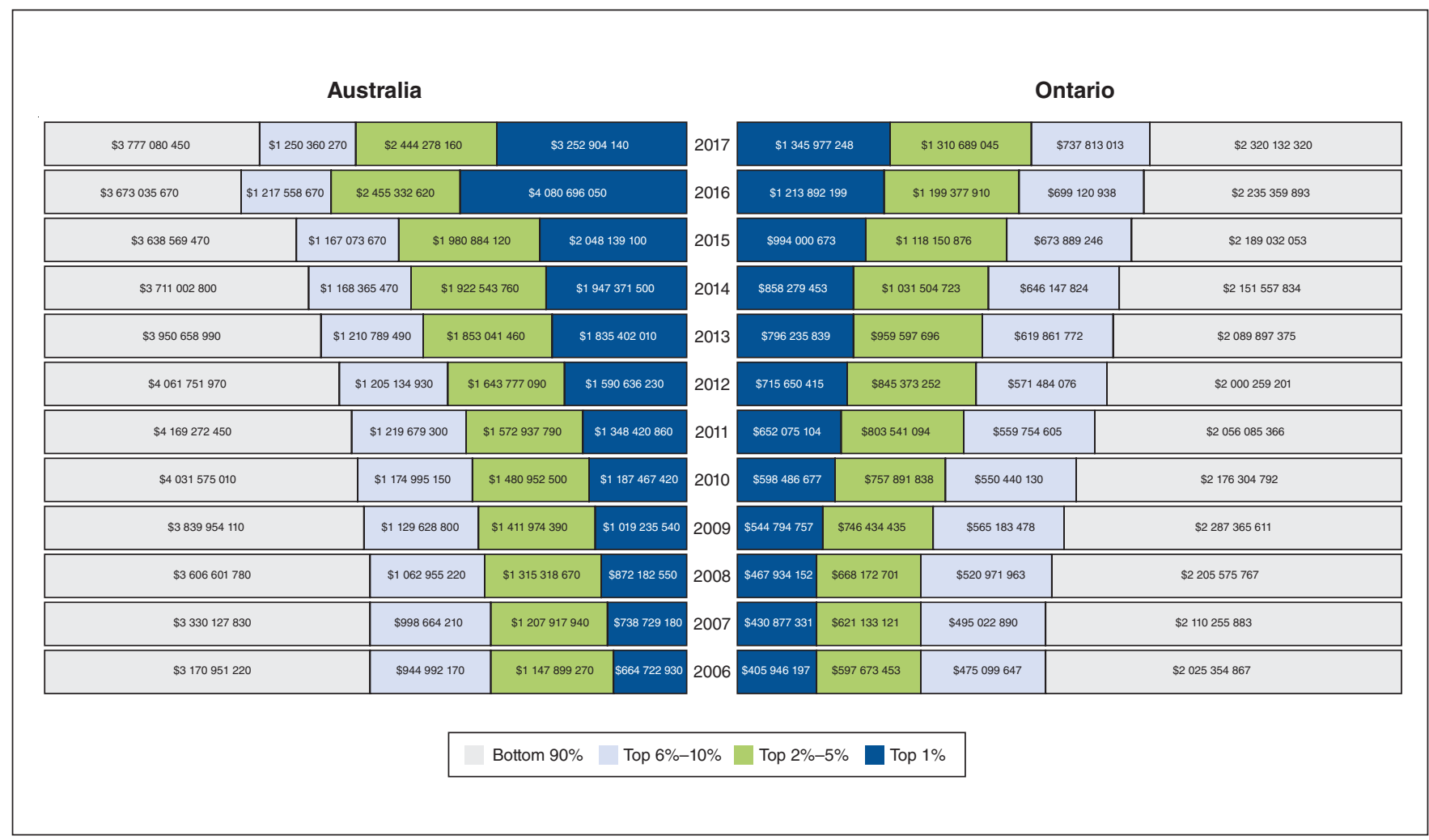

Figure 1: Drug program spending by high-drug cost beneficiary group by year from 2006 to 2017. We report costs for the Ontario data in Canadian dollars and report the Australian data in Australian dollars.

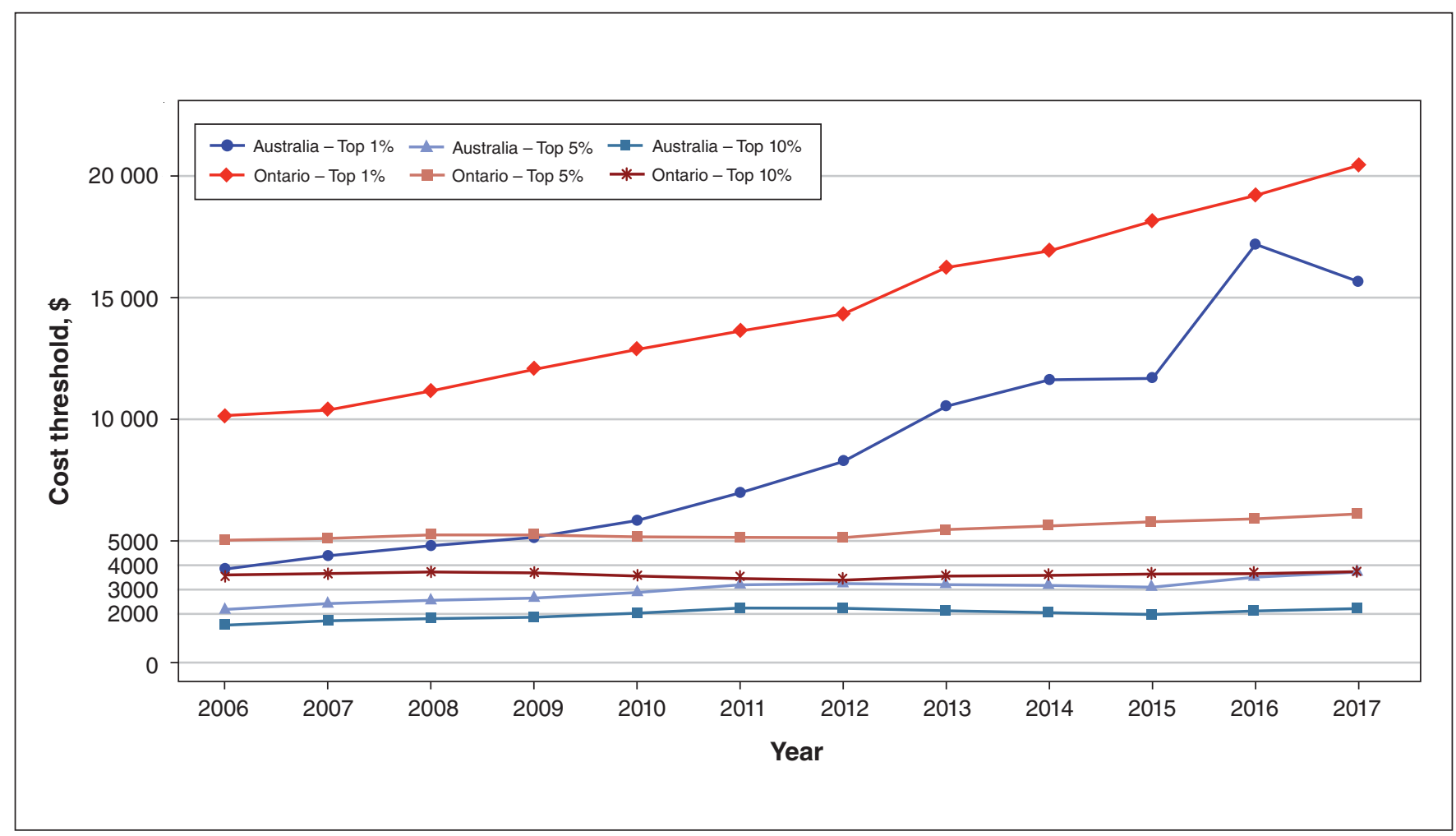

Figure 2: Cost threshold for drug spending by each high-drug cost beneficiary group in Australia and Ontario by year, from 2006 to 2017 . We report costs for the Ontario data in Canadian dollars and report the Australian data in Australian dollars. 


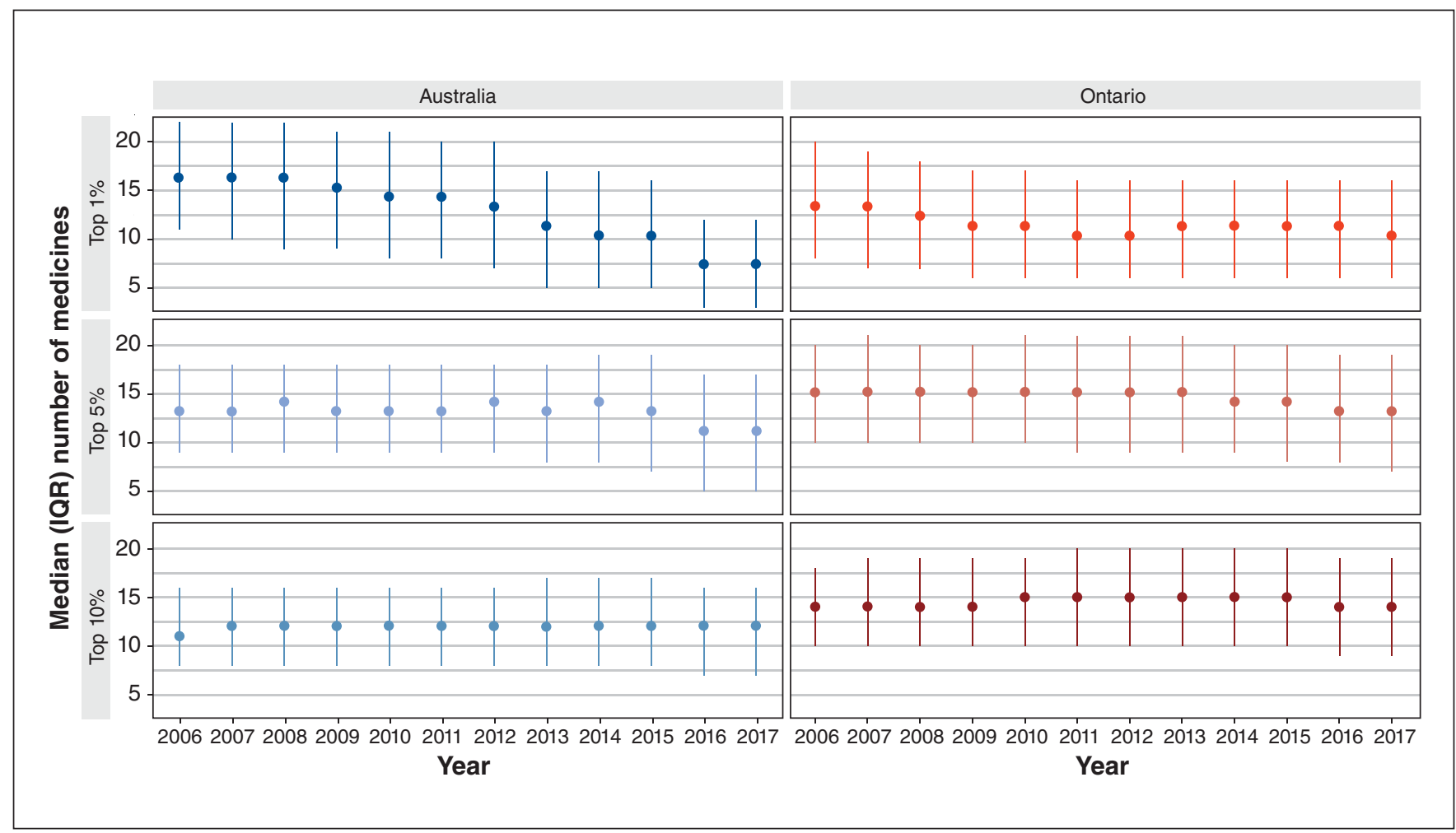

Figure 3: Median number of medications in each high-drug cost beneficiary group in Australia and Ontario from 2006 to 2017 . Note: IQR = interquartile range.

We observed a similar trend in Australia, from A\$4493 in 2006 to $A \$ 17451$ in 2017. The other 2 categories of beneficiaries also showed escalating minimum spends, but these increases were less pronounced.

In Ontario, the threshold for the top 5\% increased from $\$ 5028$ to $\$ 6110$ and, for the top $10 \%$, from $\$ 3601$ to $\$ 3737$, an increase of $21.5 \%$ and $3.8 \%$, respectively. In Australia, the threshold for the top 5\% grew from \$2552 in 2006 to $\$ 3741$ in 2017 , and from $\$ 1797$ to $\$ 2231$ for the top $10 \%$, an increase of $46.6 \%$ and $24.2 \%$, respectively. Trends remained the same when dollars were all converted to Canadian dollars.

\section{Number of medications per beneficiary}

The median number of unique medications dispensed per person annually during the study period across the high-cost beneficiary groups is shown in Figure 3. In general, the number of medications used by the top $1 \%$ and $5 \%$ of beneficiaries decreased over time in both jurisdictions. In Ontario, the median dropped from 13 to 10 in the top $1 \%$, and from 15 to 13 in the top $5 \%$. Similarly, in Australia, the median number of medications declined from 13 to 7 from 2006 to 2017 for the top 1\%, and from 13 to 8 for the top 5\%. We did not see any decreases in the top $10 \%$ group, where the median number of medications remained at 11 or 12 annually in Australia, and at 14 or 15 in Ontario.

\section{Top nine drugs by cost in $\mathbf{5 \%}$ group}

Over the study period, both jurisdictions saw a shift in the top 9 most costly medications away from common chronic medications to antivirals, ophthalmologic agents and immunosuppressants (Figure 4; Appendix 1, available at www.cmajopen.ca/content/9/4/E1048/suppl/DC1). In 2006, the highest drug spending in both Ontario and Australia was for lipid-modifying agents, followed by drugs for acid-related disorders. However, in 2017, spending was highest for antivirals followed by opthalmologicals in Australia, and for opthalmologicals followed by drugs for diabetes in Ontario.

\section{Interpretation}

In our study, we found that a small percentage of beneficiaries accounted for a substantial proportion of public drug spending in both Ontario and Australia, and that this phenomenon has become more pronounced over time. Importantly, the drug costs incurred by the top $5 \%$ of high-drug cost beneficiaries represent about half of the annual spend by public drug programs. We found important similarities and differences across both jurisdictions in the extent to which highdrug cost beneficiaries contribute to overall public drug expenditure and how this clustering has increased over time. The higher extent of clustering in Australia, with its universal population of beneficiaries, highlights the impact of a broader program. The findings underscore the impact of 2 factors contributing to clustering of high-drug cost beneficiaries, namely patients receiving expensive medications, such as antivirals and biologics, and patients receiving a greater number of medications. Understanding drug- and disease-specific issues will be important in the effort to develop robust and sustainable public drug programs. 


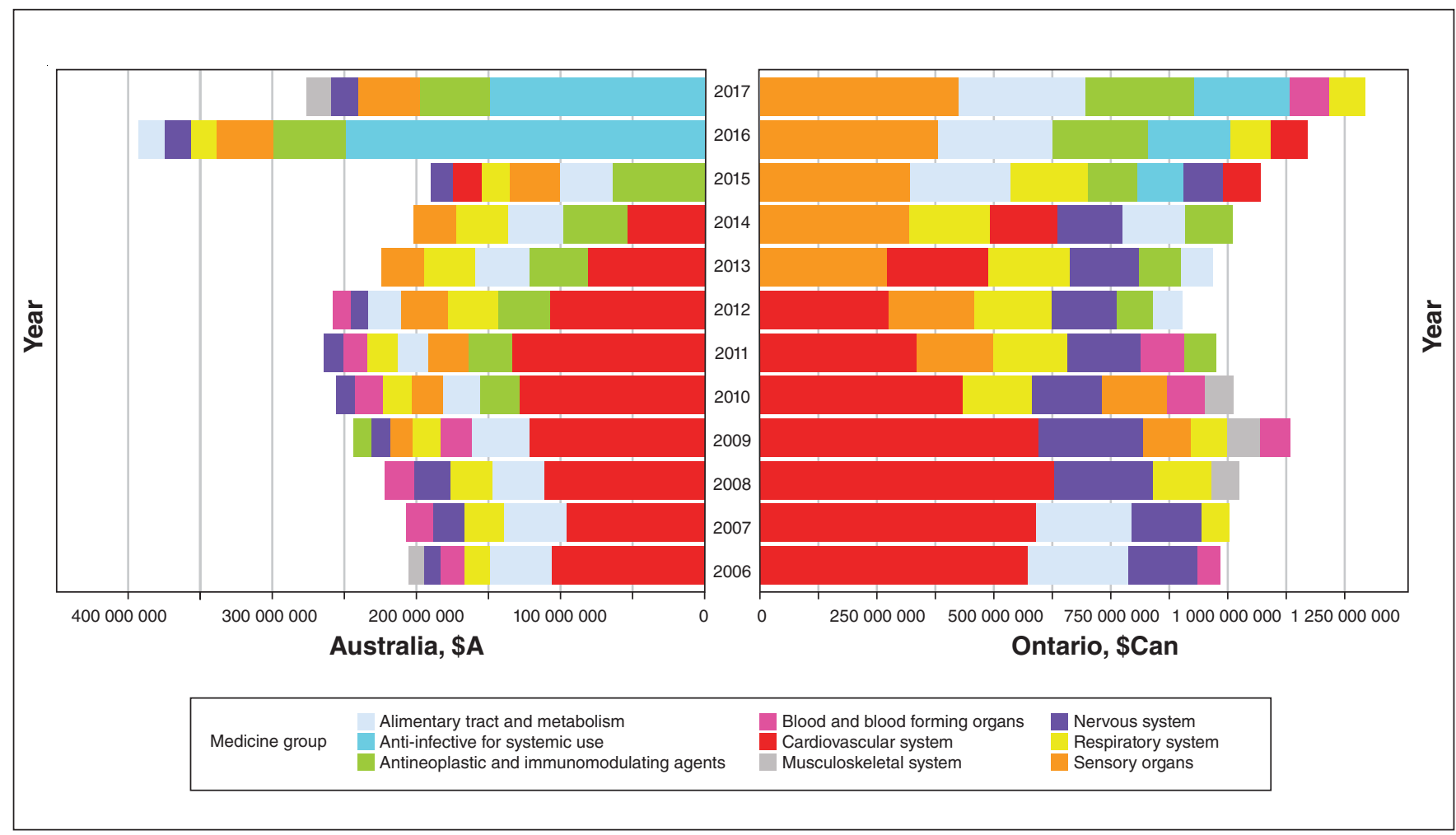

Figure 4: Top 9 drug classes (classified according to Anatomical Therapeutic Chemical categories) by spending among the top 5\% high-drug cost beneficiaries in Australia and Canada from 2006 to 2017.

Our results highlight that the number of high-cost drugs has increased substantially since $2006 .{ }^{23}$ The rising price for new medicines has created a situation whereby patients dispensed a new treatment with a price greater than $\$ 10000$ (A $\$$ or Can\$) would likely find themselves among the top 5\% of beneficiaries. This situation is clearly illustrated by the introduction of novel, direct-acting antiviral medications for hepatitis C in both Australia and Ontario. Specifically, the newly approved medications in this drug class cost $\mathrm{A} \$ 1250$ per dose, and its listing on the PBS in 2016 saw a large pool of patients with hepatitis $C$ receive a therapeutic course of the treatment, resulting in a jump in the minimum cost threshold to be included in the top $1 \%$ of beneficiaries. A similar increase occurred in Ontario with the broader introduction of these agents in 2017. ${ }^{15}$ In Canada, the annual number of drugs approved by Health Canada with costs over $\$ 10000$ increased from 20 drugs in 2005 to 163 drugs in 2017.

Importantly, although both Canada and Australia have similar health-technology assessments to determine the price of new drugs, they still may have divergent decisions and reimbursement structures. ${ }^{24,25} \mathrm{We}$ anticipate that the trend observed in our study of smaller proportions of high-cost beneficiaries increasingly driving total medicine expenditures will grow in both Canada and Australia with the availability of expensive medications. These treatments raise concerns for the sustainability of public drug programs and present challenges for contemporary funding bodies and policy-makers. The importance of developing strategies that address the impact of rising costs of new medications on government budgets, ${ }^{26,27}$ and that align with similar findings from Canada and internationally across different payer types, will help to curb rapidly rising costs. ${ }^{10,12,18,20,23}$

Australia has a national medicines policy, ensuring responsiveness to the population's needs, universal access to prescribed medicines and the quality use of those medicines in the community. The Pharmaceutical Advisory Committee plays a large role in Australia's affordable access to medicines by recommending the public subsidy of new medications based on those agents' clinical and cost-effectiveness ("value for money") compared with existing treatments, a similar process to Canada's Health Technology Assessment processes. NPS Medicine Wise (formerly the National Prescribing Service) is the implementation arm of Australia's national medicines policy, and its primary role is educating physicians and the community about the appropriate use of medicines listed on the PBS. This framework was designed to facilitate sustainable public access to new treatments and to ensure that medicines are used in line with best-practice evidence. However, our study shows that, even with such structures in place, expensive new medicines can have substantial impacts on medicine budgets. ${ }^{17,28}$ Our findings highlight that the highest cost beneficiaries in Australia have shifted from those with conditions requiring multiple medications, to those using fewer, but more costly, new treatments over the past decade. This is not from people using fewer medicines, as recent data from Australia also indicate that people who take multiple medicines continue to represent a sizable proportion of PBS beneficiaries. Instead, our results suggest that both high-cost 
users and multiple-medicine users will continue to pressure public medicine funding for the foreseeable future..$^{29}$ For example, given the national scope of coverage, Australia has been able to launch a national strategy, the Biosimilar Awareness Initiative, to improve the uptake of lower cost, biosimilar formulations for biologic medicines, the use of which is currently low in both Australia and Ontario. ${ }^{30}$

Our findings offer important insights for Canadian policymakers. This study comes as the Canadian federal government explores the potential for a universal pharmacare policy, recently announcing the launch of a national drug agency to develop a national formulary. ${ }^{31}$ Our results emphasize the potential impact of expanded coverage that is similar to the universal Australian model ${ }^{32}$ This universal model allows the inclusion of healthier patients that may not require medications, diluting the risk, which in turn further clusters the proportion of total spending to a small number of beneficiaries. Understanding what populations are more likely to be high-drug cost beneficiaries and what drugs these beneficiaries are prescribed will help inform any expansion in Canada. Expansion of these issues to a national level would allow for the development of pan-Canadian policies and initiatives that could prove to be cost-saving. For example, national strategies related to price listing agreements, similar to the pan-Canadian pharmaceutical alliance, are proven to incur cost savings. ${ }^{33,34}$ This will allow the opportunity to make decisions on the cost-effectiveness of treatments at a truly universal level and to evaluate the costeffectiveness of drugs throughout their lifecycle.

Policy-makers in Canada should consider this opportunity to develop national strategies that explore other mechanisms to address high drug costs. Importantly, the development of a national formulary would allow for initiatives related to ongoing formulary modernization to ensure appropriate use of costly medications throughout the life cycle of drugs and not just at market entry. $.35,36$ Additionally, a national strategy would create a larger market with the capacity to negotiate lower prices.

Differences between Australia and Ontario in the major cost drivers also inform important potential policy options. For example, biologic ophthalmological treatments for age-related macular degeneration were among the top 10 most costly therapeutic subgroups in both Australia and Canada; however, they accounted for a much larger proportion of spending in Canada because of different listing arrangements between the jurisdictions. Australia subsidizes a lower cost formulation as the firstline treatment, allowing for large cost-savings. ${ }^{15}$ In Canada, ranibizumab is the only formulation covered for age-related wet macular degeneration. In contrast, Australia was one of the first public payers in 2016 to allow full access to costly hepatitis $\mathrm{C}$ treatments, which substantially increased medicines expenditures during that year and in 2017. A similar national policy was enacted in Canada in 2017 for these medicines, but needed coordination across provinces. It is likely that having a national formulary would have made it easier to develop a national policy to address this major investment.

Our results also highlight that, in both jurisdictions, there is a group of high-drug cost beneficiaries whose high drug costs are a result of their use of many medicines, as opposed to a single, expensive treatment. These are likely patients with high comorbidity burdens or complex treatment needs. Approaches to address the high costs among patients who are receiving a large number of chronic medications requires interventional approaches beyond pricing policies. ${ }^{9}$ Development of initiatives to improve the prescribing practices for these patients may help to optimize their use of medications. National initiatives, such as case management and academic detailing, have been shown to help improve prescribing for complex patients. ${ }^{37-40}$ These types of initiatives are essential to both improving the safety and appropriateness of prescribing while also containing drug costs. The development of national programs may help to ensure more cost-effective use of resources to launch these programs, which may prove to be especially resource intensive for smaller provinces.

\section{Limitations}

We included only beneficiaries who had at least 1 drug claim paid by a public drug program in a given year in Ontario or Australia as we do not have data on program eligibility for Ontario. Therefore, we did not include beneficiaries who were eligible for benefits, but who did not have a drug claim. Our analysis was limited to public drug claims and we did not have information on treatment indication or other clinical data. We have inferred the extent of comorbidities based on the dispensed medicine and number of claims. This is a validated method of assessing comorbidity when only drug claims data are available. ${ }^{41}$ Additionally, we based drug indication on the Anatomical Therapeutic Chemical drug class system, which uses the initial indication of the drug to classify drugs. Some drugs may be used across indications; thus, the intended use for a specific patient may not be correctly captured. Future work should explore differences in indication and drug use among well-defined subpopulations. All of the information on drug pricing is based on the total amount reimbursed by the government. This information does not account for confidential negotiated prices or rebates received; thus, the costs reported in some drug classes may be overestimates.

\section{Conclusion}

The results of our study show that small groups of high-drug cost beneficiaries - both those using a small number of very expensive drugs and those using many treatments - drive overall drug expenditures in both Ontario and Australia. Any policy must account for the impact of individual, high-cost drugs and of complex patients. This includes strategies to address the use of costly medications, as well as the use of a large number of medications.

\section{References}

1. Prescribed drug spending in Canada, 2018. Ottawa: Canadian Institute for Health Information; 2018.

2. National health expenditure trends, 1975-2018. Ottawa: Canadian Institute for Health Information; 2018.

3. Fernandes A. A perspective on the OECD report "Health at a Glance 2019" [article in Portuguese]. Acta Med Port 2020;33:4-6.

4. Health at a Glance 2019: OECD indicators. Paris: Organisation for Economic Co-operation and Development; 2019. 
5. Protecting Canadians from excessive drug prices: consulting on proposed amendments to the patented medicines regulations. Ottawa: Health Canada; 2017.

6. Tadrous M, Martins D, Mamdani MM, et al. Characteristics of high-drug-cost beneficiaries of public drug plans in 9 Canadian provinces: a cross-sectional analysis. CMA7 Open 2020;8:E297-303.

7. de Oliveira C, Cheng J, Chan K, et al. High-cost patients and preventable spending: a population-based study. 7 Natl Compr Canc Netw 2020;18:23-31.

8. Figueroa JF, Zhou X, Jha AK. Characteristics and spending patterns of persistently high-cost Medicare patients. Health Aff (Millwood) 2019;38:107-14.

9. Joynt KE, Figueroa JF, Beaulieu N, et al. Segmenting high-cost Medicare patients into potentially actionable cohorts. Healthc (Amst) 2017;5:62-7.

10. Muratov S, Lee J, Holbrook A, et al. Regional variation in healthcare spending and mortality among senior high-cost healthcare users in Ontario, Canada: a retrospective matched cohort study. BMC Geriatr 2018;18:262.

11. Rosella LC, Fitzpatrick T, Wodchis WP, et al. High-cost health care users in Ontario, Canada: demographic, socio-economic, and health status characteristics. BMC Health Serv Res 2014;14:532.

12. Wammes JJG, van der Wees PJ, Tanke MAC, et al. Systematic review of high-cost patients' characteristics and healthcare utilisation. BMF Open 2018;8:e023113.

13. Brandt J, Shearer B, Morgan SG. Prescription drug coverage in Canada: a review of the economic, policy and political considerations for universal pharmacare. 7 Pharm Policy Pract 2018;11:28.

14. Mellish L, Karanges EA, Litchfield MJ, et al. The Australian Pharmaceutical Benefits Scheme data collection: a practical guide for researchers. BMC Res Notes 2015;8:634.

15. Louis WJ, O'Callaghan CJ, Krum H, et al. Pharmaceutical Benefits Scheme (PBS). Med 7 Aust 1994;160:306-7.

16. Levy AR, O'Brien BJ, Sellors C, et al. Coding accuracy of administrative drug claims in the Ontario Drug Benefit database. Can 7 Clin Pharmacol 2003;10:67-71.

17. Pharmaceutical Benefits Advisory Committee (PBAC). Canberra (AU): Australian Government Pharmaceutical Benefits Scheme; 2017.

18. Wodchis WP, Austin PC, Henry DA. A 3-year study of high-cost users of health care. CMA7 2016;188:182-8

19. Rais S, Nazerian A, Ardal S, et al. High-cost users of Ontario's healthcare services. Healthc Policy 2013;9:44-51.

20. Weymann D, Smolina K, Gladstone EJ, et al. High-cost users of prescription drugs: a population-based analysis from British Columbia, Canada. Health Serv Res 2017;52:697-719.

21. Guilcher SJT, Bronskill SE, Guan J, et al. Who are the high-cost users? A method for person-centred attribution of health care spending. PLoS One 2016;11:e0149179.

22. Pratt NL, Kerr M, Barratt JD, et al. The validity of the Rx-Risk Comorbidity Index using medicines mapped to the Anatomical Therapeutic Chemical (ATC) Classification System. BMF Open 2018;8:e21122.

23. Private drug plans in canada: high-cost drugs and beneficiaries, 2005 to 2015. Ottawa: Patented Medicine Prices Review Board; modified 2016 Apr. 18.

24. Wang T, McAuslane N, Liberti L, et al. Companies' health technology assessment strategies and practices in Australia, Canada, England, France, Germany, Italy and Spain: an industry metrics study. Front Pharmacol 2020;11:594549.

25. Allen N, Walker SR, Liberti L, et al. Health Technology Assessment (HTA) case studies: factors influencing divergent HTA reimbursement recommendations in Australia, Canada, England, and Scotland. Value Health 2017;20:320-8

26. Morgan SG, Li W, Yau B, et al. Estimated effects of adding universal public coverage of an essential medicines list to existing public drug plans in Canada. CMA7 2017;189:E295-302.

27. Should developed countries, including Canada, provide universal access to essential medications through a national, publicly funded and administered insurance plan? Can 7 Hosp Pharm 2016;69:167-70.

28. Vitry A, Mintzes B, Lipworth W. Access to new cancer medicines in Australia: dispelling the myths and informing a public debate. 7 Pharm Policy Pract 2016;9:13.

29. Daniels B, Wylie C, Pearson S-A, et al. A day in the life: prescription medicine use in Australia. Hoboken (NJ): Wiley:545.

30. Ward M, Lange SR, Staff K. Literature review of international biosimilar medicines: update Fune-September 2016. Canberra (AU): Department of Health.

31. A prescription for Canada: achieving pharmacare for all: final report of the Advisory Council on the Implementation of National Pharmacare. Ottawa: Health Canada; 2019.

32. Campbell DJT, Manns BJ, Soril LJJ, et al. Comparison of Canadian public medication insurance plans and the impact on out-of-pocket costs. CMAJ Open 2017;5:E808-13.

33. Morgan SG, Friesen MK, Thomson PA, et al. Use of product listing agreements by Canadian provincial drug benefit plans. Healthc Policy 2013;8:45-55.

34. Ontario public drug programs. Chapter 3, section 3.09, Ministry of Health and Long-Term Care. Toronto: Queen's Printer for Ontario; 2017. Available: www.auditor.on.ca/en/content/annualreports/arreports/en17/v1_309en17.pdf (accessed 2020 June 20).
35. Kesselheim AS, Avorn J, Sarpatwari A. The high cost of prescription drugs in the United States: origins and prospects for reform. 7AMA 2016;316:858-71.

36. Flannery AH, Pandya K, Laine ME, et al. Managing the rising costs and high drug expenditures in critical care pharmacy practice. Pharmacotherapy 2017 37:54-64.

37. Schore JL, Brown RS, Cheh VA. Case management for high-cost Medicare beneficiaries. Health Care Financ Rev 1999;20:87-101.

38. Fireman B, Bartlett J, Selby J. Can disease management reduce health care costs by improving quality? Health Aff (Millwood) 2004;23:63-75.

39. Crowley JS, Ashner D, Elam L. Medicaid outpatient prescription drug benefits: findings from a national survey, 2003. San Francisco: Henry J. Kaiser Family Foundation; 2003

40. Swanson J, Weissert WG. Case managers for high-risk, high-cost patients as agents and street-level bureaucrats. Med Care Res Rev 2018;75:527-61.

41. Yurkovich M, Avina-Zubieta JA, Thomas J, et al. A systematic review identifies valid comorbidity indices derived from administrative health data. 7 Clin Epidemiol 2015;68:3-14.

Affiliations: Leslie Dan Faculty of Pharmacy (Tadrous, Gomes), University of Toronto; Women's College Research Institute (Tadrous), Women's College Hospital; ICES Central (Tadrous, Gomes), Toronto, Ont.; Medicines Policy Research Unit (Daniels, Pearson), Centre for Big Data Research in Health, UNSW Sydney; Menzies Centre for Health Policy (Pearson), University of Sydney, New South Wales, Australia; Li Ka Shing Knowledge Institute (Gomes), St. Michael's Hospital; Institute of Health Policy, Management and Evaluation (Gomes), University of Toronto, Toronto, Ont.

Contributors: All of the authors contributed to the conception and design of the work, acquired and analyzed data, and were involved in interpretation of data. All of the authors drafted the manuscript, revised it critically for important intellectual content, gave final approval of the version to be published and agreed to be accountable for all aspects of the work.

Funding: This study was funded by the Ontario Ministry of Health and Australia's National Health and Medical Research Council Centre of Research Excellence in Medicines Intelligence.

Content licence: This is an Open Access article distributed in accordance with the terms of the Creative Commons Attribution (CC BY-NC-ND 4.0) licence, which permits use, distribution and reproduction in any medium, provided that the original publication is properly cited, the use is noncommercial (i.e., research or educational use), and no modifications or adaptations are made. See: https://creativecommons.org/licenses/ by-nc-nd/4.0/

Data sharing: The Ontario data set from this study is held securely in coded form at ICES. Although data-sharing agreements prohibit ICES from making the data set publicly available, access may be granted to those who meet prespecified criteria for confidential access, available at https://www.ices.on.ca/DAS. The full data set creation plan and underlying analytic code are available from the authors upon request, with the understanding that the computer programs may rely upon coding templates or macros that are unique to ICES and therefore either are inaccessible or may require modification. In Australia, data access was granted by the Services Australia External Request Evaluation Committee (approval number RMS0002). Direct access to the data and analytical files to other individuals or authorities is not permitted without the express permission of the approving human research ethics committees and data custodians.

Supplemental information: For reviewer comments and the original submission of this manuscript, please see www.cmajopen.ca/content/9/4/ E1048/suppl/DC1

Disclaimer: This study was supported by ICES, which is funded by an annual grant from the Ontario Ministry of Health (MOH). Parts of this material are based on data and information compiled and provided by $\mathrm{MOH}$ and the Canadian Institute of Health Information. The opinions, results and conclusions reported in this article are those of the authors and are independent from the funding sources. No endorsement by the Ontario $\mathrm{MOH}$ is intended or should be inferred. 